\title{
Bird flu: if or when? Planning for the next pandemic
}

\author{
Chloe Sellwood, Nima Asgari-Jirhandeh, Sultan Salimee
}

Postgrad Med J 2007;83:445-450. doi: 10.1136/pgmj.2007.059253

Avian influenza or "bird flu" is causing increasing concern across the world as experts prepare for the possible occurrence of the next human influenza pandemic. Only influenza $A$ has ever been shown to have the capacity to cause pandemics. Currently $\mathrm{A} / \mathrm{H} 5 \mathrm{~N} 1$, a highly pathogenic avian influenza virus, is of particular concern. Outbreaks of this disease in birds, especially domestic poultry, have been detected across Southeast Asia at regular intervals since 2003, and have now affected parts of Africa and Europe. Many unaffected countries across the world are preparing for the possible arrival of HPAl $\mathrm{A} / \mathrm{H} 5 \mathrm{NI}$ in wild birds and poultry within their territories. All such countries need to prepare for the rare possibility of a small number of human cases of HPAI A/H5N1, imported through foreign travel. Although it is by no means certain that HPAI A/ $\mathrm{H} 5 \mathrm{~N} 1$ will be the source of the next pandemic, many countries are also preparing for the inevitable occurrence of human pandemic influenza.

See end of article for authors' affiliations

Correspondence to:

Dr Chloe Sellwood

Pandemic Influenza Office, Health Protection Agency

Centre for Infections, 61

Colindale Avenue, London

NW9 5EQ, UK; chloe.

sellwood@hpa.org.uk

Received 1 March 2007

Accepted 24 April 2007 n inter-pandemic periods, influenza is typically a disease of the colder (winter) months in both the northern and southern hemisphere, with low-level transmission during the summer months $s^{1-7}$ and an annual increase each winter, ${ }^{8-13}$ which sometimes reaches epidemic proportions. The emergence of a pandemic virus is not controlled by seasonality to the same extent, although in the 1918-19 pandemic the second and by far the largest wave of infection occurred in the northern hemisphere in autumn 1918 at the start of the winter season. In the UK a similar phenomenon was observed when the A/H3N2 virus emerged in late 1968, but produced a large pandemic wave in autumn 1969. ${ }^{14-16}$

Only influenza A has ever been shown to have the capacity to cause pandemics; influenza $\mathrm{B}$ is mainly responsible for outbreaks among school children or in nursing homes, and influenza $\mathrm{C}$ is but one of the 150 or so viruses which together are responsible for the common cold. Influenza A viruses exist as many antigenically distinct subtypes in nature, and it is antigenic shift, associated with a change in the haemagglutinin $(\mathrm{H})$ antigen on the surface of the virus, with or without a concomitant change in the neuraminidase $(\mathrm{N})$ antigen, which can give rise to a pandemic.

Influenza A has been responsible for at least five human pandemics, the most well documented being during the 20th century, in 1918-19, 195758 and 1968-69. These pandemics are known to have been due to influenza A subtypes $\mathrm{HINl},{ }^{17}{ }^{18}$ $\mathrm{H} 2 \mathrm{~N} 2^{19}$ and $\mathrm{H} 3 \mathrm{~N} 2{ }^{20}$ respectively. Furthermore, retrospective serological analysis has indicated that A/H2N2, which circulated from around 1889 until 1901, was probably responsible for a pandemic which began in 1889, and that a mild pandemic in 1900 may have been caused by A/ H3N8. Influenza A/HINl may have circulated from around 1908 onwards. ${ }^{21-26}$ It is apparent, therefore, that at least two of the 20th century pandemics (in 1918 and 1957) were associated with the reemergence of viruses similar to those which had circulated previously, a process known as antigenic recycling. ${ }^{27}$ According to this theory, it is a serious possibility that the next pandemic will be derived from an $\mathrm{H} 2$ subtype, and not HPAI A/H5N1.

In order for an influenza A virus to be capable of causing a pandemic it must fulfil four criteria: it must represent a new A subtype where either the haemagglutinin antigen is unrelated to its immediate (pre-pandemic) predecessor (for example, H2) or it is almost entirely novel to humans (for example, H5); there must be little or no preexisting immunity in the population; it must cause significant clinical illness; and it must be able to spread efficiently from person to person (table 1).

Analysis of the excess- and age-specific mortality caused by 20th century pandemics reveals a pattern that is so variable that it is not possible to extrapolate with sufficient certainty to predict these features for a subsequent pandemic. Excess mortality varied from an estimated 40-50 million worldwide in 1918-19 to 1 million worldwide in 1957$58 .^{28}$ The $1968-69$ pandemic was similar to $1957-58$ in terms of excess mortality, and to later seasons when severe seasonal influenza activity (for example, 1976) occurred over the winter season. ${ }^{29}{ }^{30}$

The majority of influenza deaths in interpandemic years are in the elderly, with some reported in infants and young children. ${ }^{31}{ }^{32} \mathrm{~A}$ similar pattern occurred in the first quarter of 1918 in England and Wales; however, in the fourth quarter of that year, during the second wave of the pandemic, this pattern was reversed and the greatest mortality was in persons aged 25-29 years. ${ }^{33}$ Similar trends were observed during the pandemics in 1957-58 and 1968-69, although to a far lesser degree. While the majority of excess deaths during these two pandemics occurred among elderly persons, the relative increase in deaths was greatest among young adults. ${ }^{34-37}$ There is some evidence that the very elderly may have been partially protected in the pandemics of 195758 and 1968-69 as they had been in 1918-19. ${ }^{38} 39$ This may have been due to the fact that persons in this age group were exposed to similar antigens as children or young adults and so retained a partial immunity in later life, in effect the immunological consequences of antigenic recycling. ${ }^{27}$ 
Table 1 Pre-requisites for a pandemic

\begin{tabular}{ll}
\hline & H5N1 \\
\hline New influenza A sub-type: haemagglutinin (H) & $\checkmark$ \\
unrelated to immediate (pre-pandemic) predecessor & \\
Little or no pre-existing population immunity & $\checkmark$ \\
Causes significant clinical illness & $\checkmark$ \\
- Efficient person-to-person spread & $\mathrm{X}$ \\
\hline
\end{tabular}

In order to avoid unnecessary duplication with previous review articles of the epidemiology and clinical impact of pandemic influenza, this article will hereafter concentrate on the present threat from highly pathogenic avian influenza (HPAI) A/H5Nl and planning for the next pandemic.

\section{PRESENT SITUATION}

Currently HPAI A/H5Nl has infected and killed poultry flocks and wild waterfowl across Southeast Asia, parts of Africa and Eastern Europe. Since early 2006 there have been isolated occurrences of the disease in both poultry and wild birds across Europe as well as some human cases outside of Southeast Asia. ${ }^{40}{ }^{41}$ It is by no means certain that $\mathrm{A} / \mathrm{H} 5 \mathrm{Nl}$ will cause the next human influenza pandemic; however, most experts predict that the most likely source of the next pandemic will be Southeast Asia. At the time of writing, HPAI A/H5Nl has been responsible for over 290 human infections, of which over 170 were fatal (11 April 2007), and is regarded as a strong contender to give rise to the next human influenza pandemic. This is especially so because data continue to emerge which illustrate that the virus is actively undergoing a process of genetic diversification and change, with three phylogenetically distinct clades having already been clearly recognised. ${ }^{42}{ }^{43}$ The influenza viruses responsible for previous human pandemics have sequentially been identified as H2N2, H3N8, H1N1, H2N2 and H3N2 (fig 1).

While there is evidence that the 1918 pandemic was caused by an influenza virus of avian origin, ${ }^{44}$ there is no evidence to date that the influenza A/H5 haemagglutinin protein has ever been responsible for a previous influenza pandemic.

At the time of writing, A/H5Nl fulfils three of the criteria necessary to achieve pandemic potential but does not yet have the fourth characteristic (the ability to spread efficiently from person to person), although limited, unsustained person-toperson spread among families in Indonesia and Thailand cannot be excluded. ${ }^{45} 46$ Even if $\mathrm{A} / \mathrm{H} 5 \mathrm{Nl}$ were to achieve the final characteristic necessary to cause a pandemic, it is considered fairly likely that the current virulence $(\sim 150$ deaths

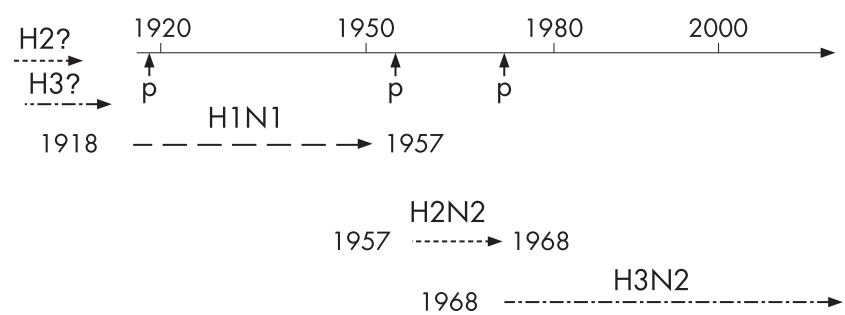

\footnotetext{
Shortest interval $=11$ years Longest interval $=39$ years Current interval $=38$ years $1977--\underline{\mathrm{H} 1 \mathrm{~N} 1}--\underset{\mathrm{H} 5}{\rightarrow}$ $\mathrm{p}=$ pandemic
}

Figure 1 Influenza A subtypes responsible for pandemics during the 20th century. out of $\sim 250$ cases) will decrease as a "trade-off" for increased transmissibility between humans.

Influenza A/H5Nl first came to worldwide attention in 1997 following a widespread outbreak in poultry flocks in Hong Kong. ${ }^{47-51}$ Despite probable wide-scale exposure of the local human population to infected poultry, clinical illness was extremely rare. Those human cases which did occur were severe, and of the 18 hospitalised cases associated with the outbreak, six subsequently died. There was no evidence of transmission between humans, and all 18 cases had contact with live or recently killed birds. ${ }^{52} 53$ The Hong Kong authorities undertook drastic control measures and culled all poultry in order to stamp out the virus, and rules were introduced around selling and handling live birds. This appeared to have been successful until the virus re-emerged in late 2003 elsewhere in Southeast Asia.

Since late 2003, HPAI A/H5Nl has been identified in poultry and wild birds across Asia, Africa and some parts of Europe. The virus reached the UK in March 2006 when a wild migratory swan, found dead at Cellardyke in Fife, Scotland, tested positive for A/H5Nl. It subsequently re-appeared in the UK in February 2007, with an outbreak of the disease on a poultry farm in the east of England, which led to the culling of over 150000 birds. ${ }^{54}$

The first human cases associated with the current outbreaks were reported in Vietnam in December 2003. ${ }^{55}$ Subsequently, a pre-dated case was reported in China, in a 24-year-old member of the military based in Beijing in November 2003. ${ }^{56}$ Human cases of $\mathrm{A} / \mathrm{H} 5 \mathrm{Nl}$ in increasing number have been reported from countries across the world since 2003 (fig 2), with the majority of cases in Indonesia and Thailand. Almost all such cases have been attributed to direct exposure to infected birds. Furthermore, although extensive studies have not yet been undertaken, data exist that HPAI A/H5Nl is not causing widespread undetected asymptomatic or mild cases. This is illustrated by lower levels of seroconversion in the wider population, ${ }^{57}$ and in healthcare workers caring for $\mathrm{H} 5 \mathrm{Nl}$ patients, ${ }^{53}{ }^{58}$ although the levels are slightly higher in poultry workers. ${ }^{59}$ One paper which did identify a high frequency of mild infections in Vietnam was based on a retrospective questionnaire and was not supported by serological evidence. ${ }^{60}$

This current epidemiological situation places the world in World Health Organization pandemic alert phase 3: human infection(s) with a new subtype, but no human-to-human spread, or at most rare instances of spread to a close contact. Progression to phases 4 and 5 will be triggered by small and then larger clusters of human cases, with limited and localised person to person spread. Phase 5 indicates a substantial pandemic risk and is followed by phase 6 when there is "increased and sustained transmission in the general population" ${ }^{61}$ In the UK, for planning purposes, phase 6 has been subdivided into four UK alert levels, dependent on the extent of activity within the $\mathrm{UK}^{62}$ (table 2 ).

\section{GLOBAL PREPAREDNESS}

Countries across the world are preparing for cases of A/H5Nl in poultry or wild birds, human cases of A/H5Nl and for the next pandemic (whatever the eventual subtype). Two recent studies in early 2006 have examined pandemic influenza preparedness in Europe ${ }^{63}$ and in the Asia-Pacific region. ${ }^{64}$ The European study reported that government commitment in most European countries is strong, and levels of preparedness are generally good, although there are gaps in planning and variation between the European countries. Cooperation between neighbouring European countries needed to be improved. ${ }^{63}$

Regional approaches in the Asia-Pacific region were more polarised, with Hong Kong (SAR of China), Australia and New Zealand comparing favourably with the best European plans. 


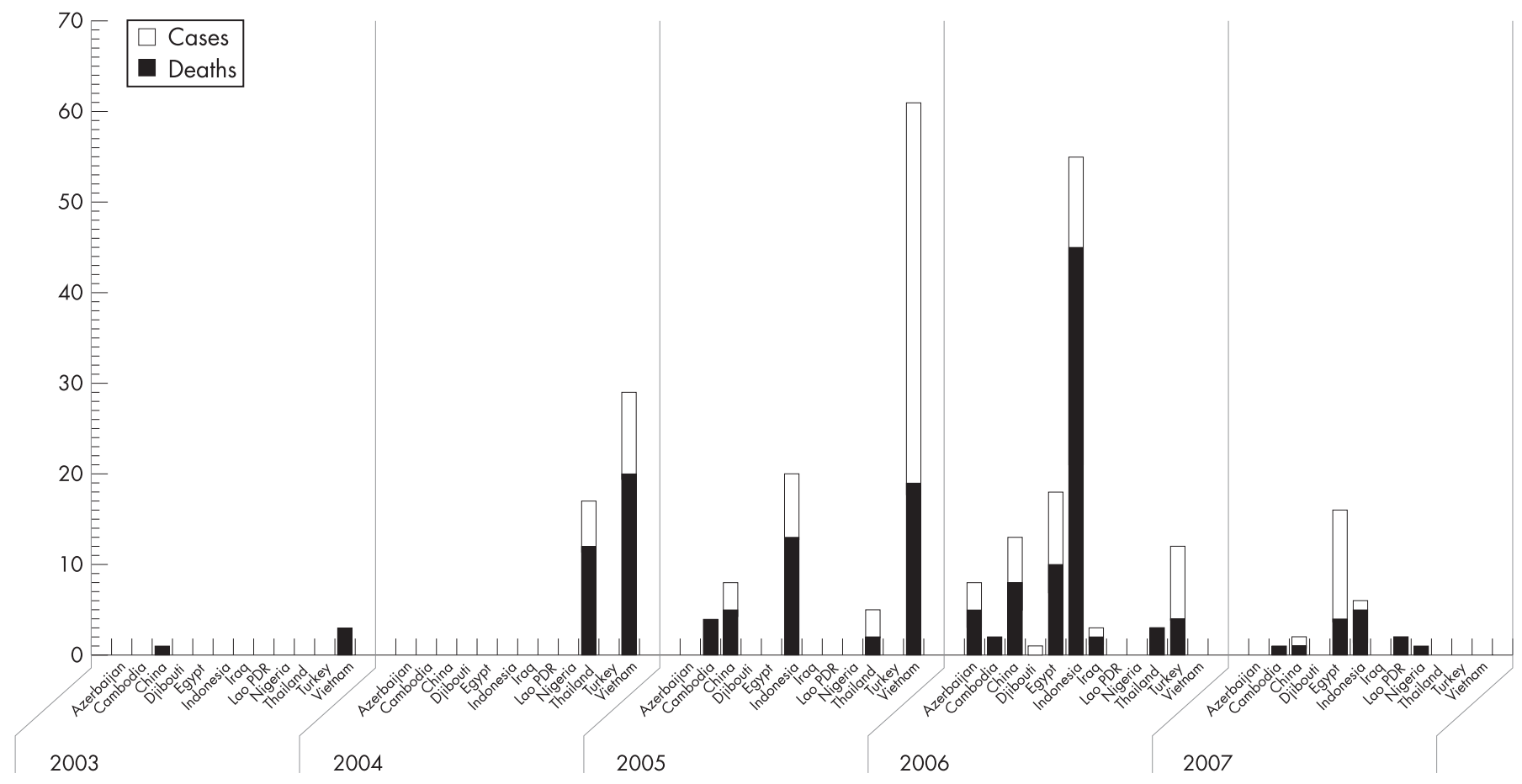

Lao PDR = Lao People's Democratic Republic

Figure 2 Human cases and fatalities from highly pathogenic avian influenza (HPAl) A/H5N1 since 2003 (until 10 April 2007).

The plans of these three countries concentrate on harnessing available resources and deploying stockpiles of vaccines and antivirals. The more resource-poor countries (Thailand, China and Vietnam) addressed issues which were largely overlooked in the European plans-mainly non-pharmaceutical interventions such as social distancing, travel restrictions and screening measures. ${ }^{64}$

The over-arching UK pandemic contingency plan has been developed by the Department of Health, based upon the global WHO plan. ${ }^{61}$ The plan is publicly available on the internet ${ }^{62}$ and was published in late 2005 with a revision due to be released in early 2007. It describes the UK strategy of considering a broad range of measures: antivirals (of which the UK has now acquired 14.6 million treatment courses); non-pharmaceutical interventions such as hand washing; voluntary isolation of cases; effective handling of contacts; and limiting non-essential travel and mass gatherings of people to minimise the impact of the pandemic while a vaccine is developed against the pandemic virus. ${ }^{62}$

The UK pandemic contingency plan is supplemented by many other plans specific to other organisations and government departments, such as the Health Protection Agency, ${ }^{65}$ and by specific guidelines for care settings such as the Guidance for pandemic influenza: infection control in hospitals and primary care settings $^{66}$ and the Clinical guidelines for patients with an influenza like illness during an influenza pandemic. ${ }^{67}$ Guidance is also being developed by the Health Protection Agency with stakeholders and the relevant government departments for non-medical care settings, such as schools, local authority domiciliary services, prisons, the emergency services and care homes. These pieces of guidance and others are considered as "living documents" to be reviewed and updated as the situation develops and as knowledge and understanding about the threat posed by A/ H5Nl advances.

The US National strategy for pandemic influenza ${ }^{68}$ was published in May 2006. The US plan focuses on three main threads: preparedness and communication; surveillance and detection; and response and containment. In contrast to the UK, the US does not yet have large stocks of antivirals available to use while a pandemic vaccine is in development, and instead will rely heavily on similar non-pharmaceutical interventions to the UK, supplemented with other measures such as school closure.

\section{PHARMACEUTICAL INTERVENTIONS}

The main defence against pandemic influenza is a vaccine matched to the pandemic strain. Development of such a vaccine would take at best 4 months from identification of the strain responsible for the pandemic, and more realistically 6 months until there were sufficient stocks available to start using the vaccine. Even then, vaccine supplies are likely to be limited for several months, due to international demand and the fulfilment of pre-orders. If the first wave of a pandemic is large, or proves to be the only wave, then in real terms there are risks that a pandemic vaccine might actually become a postpandemic vaccine. The UK government has purchased a small supply of a human $\mathrm{A} / \mathrm{H} 5 \mathrm{Nl}$ vaccine that can be used for experimental purposes and deployed in an emergency to priority groups. It is unlikely that this vaccine, as currently formulated, will be fully effective against an eventual pandemic strain, even if it were of HPAI A/H5Nl origin, as the virus will most likely change its antigenic structure as it evolves to be able to spread from person to person.

While the pandemic vaccine is being developed, other interventions will be used to try to mitigate the impact of the virus. Antivirals of the neuraminidase inhibitor class are likely to be one of the key measures against pandemic influenza, while a vaccine is being developed. The UK has purchased a stockpile of oseltamivir (Tamiflu) sufficient to treat one quarter of its population. The WHO also has a stock of this antiviral available to try to contain the first outbreaks of human pandemic influenza at the source-likely to be a resource-poor country in Southeast Asia-by treating the cases and for postexposure prophylaxis for contacts of those first cases. Neuraminidase inhibitors work by inhibiting viral replication, in particular release of newly formed virions from an infected host cell. Thus they need to be taken as early as possible 
Table 2 World Health Organization phases and UK alert levels

\section{Inter-pandemic period}

Phase 1: No new influenza virus subtypes have been detected in humans. An influenza virus subtype that has caused human infection may be present in animals. If present in animals, risk* of human infection or disease is considered to be low

Phase 2: No new influenza virus subtypes have been detected in humans. However, a circulating animal influenza virus subtype poses a substantial risk* ${ }^{*}$ human disease

\section{Pandemic alert period}

Phase 3: Human infection(s) with a new subtype, but no human-to-human spread, or at most rare instances of spread to a close contactt and response to additional cases

Phase 4: Small cluster(s) with limited human-to-human transmission but spread is highly localised, suggesting that the virus is not well adapted to humanst

Phase 5: Larger cluster(s) but human-to-human spread still localised, suggesting that the virus is becoming better adapted to humans, but may not yet be fully transmissible (substantial pandemic risk)

\section{Pandemic period}

Phase 6: Pandemic: increased and sustained transmission in general population $†$

UK Alert Level 1: Virus/cases only outside the UK

UK Alert Level 2: Virus isolated in the UK

UK Alert Level 3: Outbreak(s) in the UK

UK Alert Level 4: Widespread activity across the UK

\begin{tabular}{l} 
Post-pandemic period \\
\hline Return to inter-pandemic arrangements of phase 1 \\
*The distinction between phases 1 and 2 is based on the risk of human \\
infection or disease resulting from circulating strains in animals. The \\
distinction is based on various factors and their relative importance \\
according to current scientific knowledge. Factors may include pathogenicity \\
in animals and humans, occurrence in domesticated animals and livestock \\
or only in wildlife, whether the virus is enzootic or epizootic, geographically \\
localised or widespread, and/or other scientific parameters. \\
†The distinction between phases 3,4 and 5 is based on an assessment of the \\
risk of a pandemic. Various factors and their relative importance according \\
to current scientific knowledge may be considered. Factors may include rate \\
of transmission, geographical location and spread, severity of illness, \\
presence of genes from human strains (if derived from an animal strain), \\
and/or other scientific parameters.
\end{tabular}

following infection, certainly within the first $48 \mathrm{~h}$ of becoming infected, in order to be effective. Additional modelling studies suggest that even earlier treatment would reduce transmission to the extent that secondary population effects might also be seen ( $\mathrm{J}$ Edmunds, personal communication, 2006)

\section{NON-PHARMACEUTICAL INTERVENTIONS}

Countries which do not have access to antivirals will need to rely on other measures against the pandemic, as will those countries with only small stockpiles of antivirals. A variety of different non-pharmaceutical interventions have been considered by various international governments. Community mitigation methods concentrating on social distancing and infection control will not prevent a pandemic, but will delay its spread. A variety of measures are being considered, such as travel restrictions, school closures and community isolation.

A new pandemic might be containable at source (assumed to be Southeast Asia) through rapid, virtually immediate, application of a combination of stringent social distancing measures, area quarantine and geographically targeted antiviral prophylaxis (requiring up to three million courses of antivirals). ${ }^{69}$ However, the logistics of such an exercise will prove immensely challenging in practice; such an intervention also depends on rapid discovery of the pandemic virus, which may be difficult in countries with under developed public health infrastructures and surveillance methods. Similar containment measures to prevent a pandemic spreading in the UK are unlikely to be effective as simultaneous, multiple importations of the disease would be expected, and antiviral stocks would rapidly be depleted to little effect. ${ }^{70}$

Intuitively imposing international travel restrictions would seem like an effective means to reduce and/or delay spread of a pandemic virus. However, modelling has indicated that such measures are unlikely to delay an epidemic significantly. ${ }^{70}{ }^{71}$ Border restrictions and/or internal travel restrictions are unlikely to delay spread of the pandemic by more than 1-2 weeks if $90 \%$ effective, and by only $2-3$ weeks unless more than $99 \%$ effective. $^{70}$

Interventions to reduce local transmission of influenza are likely to be more effective at reducing the rate of global spread and less vulnerable to implementation delays than air travel restrictions. ${ }^{71}$ Furthermore, entrance screening at airports is unlikely to be effective at preventing or delaying an epidemic, as most of those who board a flight incubating influenza would not display symptoms until after arrival and so would not be prevented from entering the country. ${ }^{72}$

Implementation of school closures has also been considered as a non-pharmaceutical intervention to reduce the spread of pandemic influenza. Although this has had varied success in the past, recent modelling work indicates that school closure during the peak of a pandemic might reduce clinical peak attack rates in children by up to $40 \%$ and slow the epidemic spread to some degree. However it has little impact on overall attack rates. ${ }^{70}$ Even with school closure it is important to ensure that children do not then meet in informal networks outside of school, thereby negating any positive effect.

Most experts agree that influenza is transmitted predominantly via large droplet spread and contact spread. However, opinions are sharply divided over the additional role which might be played by aerosol spread. A recent review strongly advocated that influenza is transmitted mainly by aerosol and that droplet transmission played only a minor part. ${ }^{73}$ However, many existing papers reach the opposite conclusion and support mainly droplet spread. ${ }^{74-76}$ At the October 2006 Scientific Working Meeting on Occupational Influenza Prevention and Control in Health Care Settings, Toronto, two Canadian groups presented further reviews of influenza transmission, at least one of which is in press. Both groups concluded that that the available data are insufficient to draw any firm conclusions about the relative importance and frequency of the various modes of transmission. Both groups did, however, agree that most transmission seemed to occur at short range. The evidence base around this particular aspect of influenza biology is scanty and in need of further definitive work, a feature which makes preparing for a pandemic of influenza particularly challenging.

The discussion about the use of surgical facemasks and respirators by health care workers and the general public is ongoing across the globe. Current UK guidance advises the use of surgical masks for health care workers dealing with symptomatic patients and respirators (standard FFP3) when undertaking aerosol generating procedures. ${ }^{66}$ Additionally it is recommended that, in some circumstances (for example, in waiting areas), symptomatic patients should wear surgical masks.

Two recent trials in hospital wards undertaken by the Health Protection Agency have looked at the use of personal protective equipment (PPE) in pandemic influenza scenarios. The trials involved a general medical ward and an intensive care ward undergoing exercises, where PPE appropriate to existing guidelines for an influenza pandemic was used by staff over $24 \mathrm{~h}$ periods. The results of these studies will be used to inform the development and revision of the national infection control guidelines. ${ }^{66}$ 


\section{Key references}

- Nguyen-Van-Tam JS, Hampson AW. The epidemiology and clinical impact of pandemic influenza. Vaccine 2003;21:1762-8.

- Ferguson NM, Cummings DA, Cauchemez $S$, et al. Strategies for containing an emerging influenza pandemic in Southeast Asia. Nature 2005;437:209-14.

- Ferguson NM, Cummings DA, Fraser $C$, et al. Strategies for mitigating an influenza pandemic. Nature 2006;442:448-52.

- Cooper BS, Pitman RJ, Edmunds WJ, et al. Delaying the international spread of pandemic influenza. PLoS Med 2006;3:e212.

- Pitman RJ, Cooper BS, Trotter CL, et al. Entry screening for severe acute respiratory syndrome (SARS) or influenza: policy evaluation. BMJ 2005;331:1242-3.

Although the human cases of infection with influenza A/ H5Nl which started in Southeast Asia are of concern, it is the risk that the same virus might evolve to produce the next pandemic which is of key concern. Pandemic planning continues to evolve, develop and be modified as more information on the developing $\mathrm{A} / \mathrm{H} 5 \mathrm{Nl}$ situation and our understanding of influenza becomes available. We will never be able to truly predict which interventions are going to be most effective, until we use them during a pandemic.

\section{ACKNOWLEDGEMENTS}

The authors would like to acknowledge the assistance of Dr Jonathan S Nguyen-Van-Tam when preparing this review.

\section{Authors' affiliations}

Chloe Sellwood, Nima Asgari-Jirhandeh, Sultan Salimee, Pandemic Influenza Office, Health Protection Agency Centre for Infections, Colindale, London, UK

Competing interests: None

\section{REFERENCES}

1 Jordan WS Jr, Denny FW Jr, Badger GF, et al. A study of illness in a group of Cleveland families XVII. The occurrence of Asian influenza. Am J Hyg 1958:68:190-212.

2 Philip RN, Bell JA, Davies DJ, et al. Epidemiologic studies on influenza in familial and general population groups, 1951-1956. II. Characteristics of occurrence. Am J Hyg 1961;73:123-37.

3 Hall CE, Cooney MK, Fox JP. The Seattle virus watch. IV. Comparative epidemiologic observations of infections with influenza A and B viruses, 19651969, in families with young children. Am J Epidemiol 1973;98:365-80.

4 Dowdle WR, Coleman MT, Gregg MB. Natural history of influenza A in the United States, 1957-1972. Prog Med Virol 1974;17:91-135.

5 Monto AS, Kioumehr F. The Tecumseh study of respiratory illness. IX. Occurrence of influenza in the community, 1966-1971. Am J Epidemiol 1975;102:553-63.

6 Pereira MS, Chakraverty P. The laboratory surveillance of influenza epidemics in the United Kingdom, 1968-1976. J Hyg Camb 1977;79:77-87.

7 Fox JP, Hall CE, Cooney MK, et al. Influenza virus infections in Seattle families, 1975-1979. I. Study design, methods and the occurrence of infections by time and age. Am J Epidemiol 1982;116:212-27.

8 Fleming DM, Crombie DL, Norbury CA, et al. Observations on the influenza epidemic of November-December 1989. Br J Gen Pract 1990;40:495-7.

9 Fleming DM. The impact of three influenza epidemics on primary care in England and Wales. Pharacoeconomics 1996;9(Suppl):38-45

10 The Birmingham Research Unit of the Royal College of General Practitioners Influenza:collective research in general practice. J $R$ Coll Gen Pract 1977;27:544-51.

11 Hope-Simpson R-E. The role of season in the epidemiology of influenza. J Hyg Camb $1981 \cdot 86: 35-47$

12 Kilbourne ED. Influenza. New York: Plenum Medical Book Co, 1987.

13 Thacker SB. The persistence of influenza A in human populations. Epidemiol Rev 1986:8:129-41.
14 Cockburn WC, DElon PJ, Ferreira W. Origin and progress of the 1968-1969 Hong Kong influenza epidemic. Bull World Health Organ 1969:41:345-8.

15 Assad F, Cockburn WC, Sundaresan TK. Use of excess mortality from respiratory diseases in the study of influenza Bull World Health Organ 1973;49:219-33.

16 Hope-Simpson RE. First outbreak of Hong Kong influenza in a general practice population in Great Britain. A field and laboratory study. BMJ 1970;3:74-7.

17 Taubenberger JK, Reid AH, Krafft AE, et al. Initial genetic characterization of the 1918 "Spanish" influenza virus. Science 1997;275:1793-6.

18 Shope RE. Swine influenza. III. Filtration experiments and aetiology. J Exp Med 1931;54:373-80.

19 Chu CM, Shao C, Hou CC. Studies of strains of influenza virus isolated during the epidemic in 1957 in Changchun. Vop Virus, 1957;B, 278-81.

20 Chang WK. National influenza experiences in Hong Kong, 1968. Bull World Health Organ 1969;41:349-51

21 Maurel N, Marine WM. Recycling of Asian and Hong Kong influenza A virus hemagglutinins in man. Am J Epidemiol 1973:97:44-9.

22 Davenport FM. Reflections on the epidemiology of myxovirus infections. Med Microbiol Immunol 1977;163:69-76

23 Rekart M, Rupnik K, Cesario TC, et al. Prevalence of hemagglutination inhibition antibody to current strains of the $\mathrm{H} 3 \mathrm{~N} 2$ and $\mathrm{H} 1 \mathrm{~N} 1$ subtypes of influenza: a virus in sera collected from the elderly in 1976. Am J Epidemiol 1982;1 15:587-97.

24 Masurel N, Heijink RA. Recycling of HIN1 influenza A virus in man - a haemagglutinin antibody study. J Hyg London 1983;90:397-402.

25 Davenport FM, Minuse E, Hennessy AV, et al. Interpretations of influenza antibody patterns of man. Bull World Health Organ 1969;41:4553-60.

26 Dowdle WR. Influenza A virus recycling revisted. Bull World Health Organ. 1999:77: 820-8, 1969:41:349-51.

27 Nguyen-Van-Tam JS, Hampson AW. The epidemiology and clinical impact of pandemic influenza. Vaccine 2003;21:1762-8

28 Potter CW. Chronicle of influenza pandemics. In: Nicholson KG, Webster RG Hay AJ, eds. Textbook of influenza. London: Blackwell Scientific Publications, 1998:3-18.

29 Ashley i, Smith T, Dunnell K. Deaths in Great Britain associated with the influenza epidemic of 1989-1990. Popul Trends 1991;65:16-20.

30 Tillett HE, Smith JWG, Gooch CD. Excess deaths attributable to influenza in England and Wales: age at death and certified cause. Int J Epidemiol 1983;12:344-52.

31 Nguyen-Van-Tam JS. Epidemiology of influenza. In: Nicholson KG, Webster RG Hay AJ, eds. Textbook of influenza. London: Blackwell Scientific Publications, 1998:181-206

32 Nicholson KG. Human influenza. In: Nicholson KG, Webster RG, Hay AJ, eds Textbook of influenza. London: Blackwell Scientific Publications, 1998:219-66.

33 HMSO. Supplement to the 81 st annual report of the Registrar General: report on the mortality from influenza in England and Wales during the epidemic of 19181919. London: HMSO, 1920:1-47.

34 Daver CC, Serfling RE. Mortality from influenza, 1957-1958 and 1959-1960. Am Rev Respir Dis 1961;83:15-28.

35 Alling DW, Blackwelder WC, Stuart-Harris H. A study of excess mortality during influenza epidemics in the United States, 1968-1976. Am J Epidemiol $1981 ; 113: 30-8$

36 Simonsen L, Schonberger LB, Stroup DF, et al. The impact of influenza on mortality in the USA. In: Brown LE, Hampson AW, Webster RG, eds. Options for the control of influenza III. Amsterdam: Elsevier, 1996:26-33.

37 Simonsen L, Clarke MJ, Schonberger LB, et al. Pandemic versus epidemic influenza mortality: a pattern of changing age distribution. $J$ Infect Dis 1998; 178:53-60

38 Payne AMM. Symposium on the Asian influenza epidemic, 1957. Proc $R$ Soc Med, 1958:51;1009-15.

39 Schoembaum SC, Coleman MT, Dowdle WR, et al. Epidemiology of influenza in the elderly: evidence of virus recycling. Am J Epidemiol 1976;103:166-7.

40 Gilsdorf A, Boxall N, Gasimov V, et al. Two clusters of human infection with influenza A/H5N1 virus in the Republic of Azerbaijan, February-March 2006. Euro Surveill 2006;11:122-6.

41 Euro Surveillance. Tenth EU country detects highly pathogenic avian influenza in wild birds. Euro Surveill 2006;11:E060309.3.

42 Smith GJ, Naipospos TS, Nguyen TD, et al. Evolution and adaptation of H5N influenza virus in avian and human hosts in Indonesia and Vietnam. Virology 2006:350:258-68.

43 World Health Organization Global Influenza Program Surveillance Network Evolution of $\mathrm{H} 5 \mathrm{~N} 1$ avian influenza viruses in Asia. Emerg Infect Dis 2005;11:1515-21.

44 Taubenberger JK, Reid AH, Lourens RM, et al. Characterization of the 1918 influenza virus polymerase genes. Nature 2005;437:889-93.

45 Kandun IN, Wibisono H, Sedyaningsih ER, et al. Three Indonesian clusters of $\mathrm{H} 5 \mathrm{~N} 1$ virus infection in 2005. N Engl J Med 2006;355:2186-94.

46 Normile D. Avian influenza. Human transmission but no pandemic in Indonesia. Science 2006;312:1855

47 de Jong JC, Claas EC, Osterhaus ADME, et al. A pandemic warning? Nature 1997;389:554.

48 Yuen KY, Chan PKS, Peiris $M$, et al. Clinical features and rapid viral diagnosis of human disease associated with avian influenza $\mathrm{A} \mathrm{H} 5 \mathrm{~N} 1$ virus. Lancet 1998:351:467-71.

49 Subbarao K, Shaw MW. Molecular aspects of avian influenza (H5N1) viruses isolated from humans. Rev Med Virol 2000; 10:337-48.

50 Claas EC, Osterhaus ADME, van Beek R, et al. Human influenza A H5N1 viruses related to a highly pathogenic avian influenza virus. Lancet 1998:351:472-7.

51 Centre for Disease Control. Update: isolation of avian influenza A (H5N1) viruses from humans - Hong Kong, 1997-1998. MMWR Morb Mort Wkly Rep 1998:46:1245-7. 
52 Webster RG, Hay AJ. The H5N1 influenza outbreak in Hong Long: a test of pandemic preparedness. In: Nicholson KG, Webster RG, Hay AJ, eds. Textbook of influenza. London: Blackwell Scientific Publications, 1998:561-5.

53 Buxton Bridges CB, Katz JM, Seto WH, et al. Risk of influenza A (H5N1) infection among healthcare workers exposed to patients with influenza $A$ (H5N1), Hong Kong. J Infect Dis 2000;181:344-8.

54 Editorial Team. Confirmed $\mathrm{H} 5 \mathrm{~N} 1$ avian influenza outbreak on a poultry farm in England, February 2007. Euro Surveill 2007;12:E070208.2.

55 World Health Organization Disease Outbreak News. Avian influenza A(H5N1) in humans and poultry in Viet Nam 2004 (13 January 2004). http:// www.who.int/csr/don/2004_01_13/en/index.html (Accessed on 6 Dec 2006).

56 World Health Organization Disease Outbreak News. Avian influenza situation in China - Update 13 (8 August 2006). http://www.who.int/csr/don/ 2006_08_08/en/index.html (Accessed on 6 Dec 2006).

57 Vong S, Coghlan B, Mardy S, et al. Low frequency of poultry-to-human H5N1 virus transmission, Southern Cambodia, 2005. Emerg Infect Dis. 2006;10, Available from http://www.cdc.gov/ncidod/EID/vol12no10/06-0424.htm.

58 Liem NT, Lim W. World Health Organization International Avian Influenza Investigation Team, Vietnam. Lack of H5N1 avian influenza transmission to hospital employees, Hanoi, 2004. Emerg Infect Dis 2005;11:210-5.

59 Bridges CB, Lim W, Hu-Primmer J, et al. Risk of influenza A (H5N1) infection among poultry workers, Hong Kong, 1997-1998. J Infect Dis 2002;185:1005-10.

60 Thorson A, Petzold M, Nguyen TK, et al. Is exposure to sick or dead poultry associated with flulike illness? : a population-based study from a rural area in Vietnam with outbreaks of highly pathogenic avian influenza, Arch Intern Med 2006;166:119-23.

61 World Health Organization. WHO global influenza preparedness plan. The role of $\mathrm{WHO}$ and recommendations for national measures before and during pandemics, World Health Organization, Geneva, 2005. Document ref: WHO/ CDS/CSR/GIP/2005, 5 http://www.who.int/csr/resources/publications/ influenza/GIP_2005_5Eweb.pdf (Accessed on 14 June 2007).

62 UK Department of Health and Cabinet Office. Pandemic influenza - a national framework for responding to an influenza pandemic. Draft for comment 2007. http://www.dh.gov.uk/en/Publicationsandstatistics/Publications/ PublicationsPolicyAndGuidance/DH_073185 (Accessed 12 April 2007).

63 Coker R, Mounier-Jack S. Pandemic influenza preparedness in the Asia-Pacific region. Lancet 2006;368:886-9.
64 Mounier-Jack S, Coker RJ. How prepared is Europe for pandemic influenza? Analysis of national plans. Lancet 2006;367:1405-11.

65 Health Protection Agency. Health Protection Agency pandemic influenza contingency plan, 2006. http://www.hpa.org.uk/infections/topics_az/ influenza/pandemic/fluplan.htm (Accessed 6 Dec 2006).

66 Department of Health, Health Protection Agency. Guidance for pandemic influenza: Infection control in hospitals and primary care settings, 2005. http:// www.dh.gov.uk/PublicationsAndStatistics/Publications/

PublicationsPolicyAndGuidance/PublicationsPolicyAndGuidanceArticle/fs/ en?CONTENT_ID = 4121752\&chk = IfHfV7 (Accessed 6 Dec 2006).

67 British Thoracic Society, British Infection Society, Health Protection Agency for the Department of Health. Clinical guidelines for patients with an influenza like illness during an influenza pandemic, 2006. http://www.dh.gov.uk/ PublicationsAndStatistics/Publications/PublicationsPolicyAndGuidance/ PublicationsPolicyAndGuidanceArticle/fs/ en?CONTENT_ID = 4121753\&chk=ZXKxus (Accessed 6 Dec 2006).

68 Homeland Security Council. National strategy for pandemic influenza: implementation plan, 2006 http://www.whitehouse.gov/homeland/ nspi_implementation.pdf (Accessed 6 Dec 2006).

69 Ferguson NM, Cummings DA, Cauchemez S, et al. Strategies for containing an emerging influenza pandemic in Southeast Asia. Nature 2005;437:209-14.

70 Ferguson NM, Cummings DA, Fraser C, et al. Strategies for mitigating an influenza pandemic. Nature 2006;442:448-52.

71 Cooper BS, Pitman RJ, Edmunds WJ, et al. Delaying the international spread of pandemic influenza. PLoS Med 2006;3:e212.

72 Pitman RJ, Cooper BS, Trotter CL, et al. Entry screening for severe acute respiratory syndrome (SARS) or influenza: policy evaluation. $B M J$ 2005;331:1242-3.

73 Tellier R. Review of aerosol transmission of influenza A virus. Emerg Infect Dis 2006;12:1657-62.

74 Bridges CB, Kuehnert MJ, Hall CB. Transmission of influenza: implications for control in health care settings. Clin Infect Dis 2003;37:1094-101.

75 Bell DM, WHO Writing Group. Nonpharmaceutical interventions for pandemic influenza, international measures. Emerg Infect Dis 2006;12:81-7.

76 Garner JS. Guideline for isolation precautions in hospitals. The Hospital Infection Control Practices Advisory Committee. Infect Control Hosp Epidemiol 1996;17:53-80. 